\title{
Correction to: Pedagogical Tasks Toward Extending Mathematical Knowledge: Notes on the Work of Teacher Educators
}

\author{
Rina Zazkis and Ofer Marmur
}

\section{Correction to:}

Chapter 5 in: M. Goos, K. Beswick (eds.), The Learning and Development of Mathematics Teacher Educators, Research in Mathematics Education, https://doi.org/10.1007/978-3-030-62408-8_5

The original version of this chapter was revised due to some errors (listed below) in the text at page numbers 98 and 99.

- On pages 98 and 99, there are incorrect “+”" symbols (with a circle around them), where this should have been an approximation symbol.

- Also on pages 98 and 99, there are two instances of wrong indentations.

The author bio of Dr. Ofer Marmur has been updated in the front matter of this book under the section "Editor and Author Biographies." 